\title{
Innovations to combat COVID-19
}

Anuruddha Padeniya ${ }^{1,2}$, Prasad Colombage ${ }^{1,3}$, Udani Navodanie $^{1}$, Nimani de Lanerolle ${ }^{1,4}$, Bhumini Karunarathna $^{1,4}$, Samantha Ananda ${ }^{1,4 *}$, Harsha Samarasinghe ${ }^{1,5}$, Naveen De Soysa ${ }^{1,6}$, Senal Fernando ${ }^{1,7}$, Haritha Aluthge, ${ }^{1,6}$, Yasindu Rathnayake ${ }^{1,7}$, Ravindu Danthanarayana ${ }^{1}$, Chandika Epitakaduwa ${ }^{1,8}$, Dineshan Ranasinghe ${ }^{1,9}$

${ }^{1}$ Government Medical Officers' Association (GMOA), Colombo, Sri Lanka; ${ }^{2}$ Lady Ridgeway Hospital, Sri Lanka; ${ }^{3}$ National Eye Hospital, Sri Lanka; ${ }^{4}$ Ministry of Health, Sri Lanka; ${ }^{5}$ Teaching Hospital Karapitiya, Sri Lanka; ${ }^{6}$ National Institute of Health Sciences, Sri Lanka; ${ }^{7}$ Base Hospital Homagama, Sri Lanka; ${ }^{8}$ Base Hospital Thambuththegama, Sri Lanka; ${ }^{9}$ Base Hospital Panadura, Sri Lanka

"Correspondence: samanthaananda@yahoo.com https://orcid.org/0000-0002-9894-6982

DOI: https://doi.org/10.4038/jccpsl.v26i5.8329

Received on 9 May 2020

Accepted on 5 June 2020

\section{Summary}

COVID-19 pandemic has at present seized the world and caused humankind to focus on survival and progression. It has caused individuals to step forward beyond their comfort zone and develop and nurture abilities and innovations to combat this novel virus. This innovation culture was evidenced in China, the epicentre of the pandemic, where multiple technological innovations helped to combat the Corona outbreak (1). In addition, scientists are also involved in biological innovations aiming to discover treatment modalities for the virus (2). Furthermore, these innovations are crucial for the sustainable development of the globe (3).

Sri Lanka, which is a lower-middle income country (LMIC) requires facilities and equipment to overcome the COVID-19 pandemic as well as to face the post-pandemic era. Innovations and interventions were produced by the scientists, innovators, software engineers, medical professionals and others interested in the vast field of innovation. The lack of a platform for these inventors to develop their inventions to a globally accepted and commercially producible level was noted. This narrative report highlights the need for new innovations to uplift the health sector and fulfilment of this requirement. 


\section{Public health response and its impact}

\section{'Innovations to Combat COVID-19 Programme'}

The Government Medical Officers' Association (GMOA) together with the Society for Health Research and Innovation (SHRI) initiated a program to assemble these innovators who are scattered throughout the island to a common platform. The programme was titled "Innovations to Combat COVID-19." Under the guidance of an expert panel consisting of a consultant cardiologist, consultant paediatrician, consultant anaesthetist, consultant community physician, scientist from Sri Lanka Institute of Nano Technology, President of the Industrial Technology Institute (ITI), Commissioner of the New Inventors Commission, Director General of the Research and Development Branch of Sri Lankan Army, Chief Executive Officer of the Society of Health Research and Innovation, Dean of the Faculty of Medicine, University of Colombo and Vice-Chancellor of the University of Colombo, a feedback was provided to improve and certify the product once it attained the standard qualifications. It was also deemed a platform where manufacturers would be introduced to the innovators to make the innovative products commercially producible. In addition, a funding process has also been instituted to safeguard the innovators financially until they reach an economically stable status. Legal guidance was also provided to secure the rights of the innovator.

At the inception, the innovators applied via a google form/electronic mail and were subsequently assessed by an expert panel consisting of several medical and technical experts. Innovators were provided with technical knowledge regarding their prototypes and proposals for the innovation. As difficulties were encountered in obtaining necessary parts for production, capable parties were brought forward to collaborate.

Subsequently, a research and development committee consisting of experts in the fields of medicine, technology and defence security was formulated. Advocacy was carried out to ensure that non-medical professionals were also included in this committee. This inclusion brought about successful inter-sectoral collaboration amongst the diverse fields of the sciences. Those who had successfully developed their prototypes were introduced to the research and development committee. Through this exercise, it was possible to give a variety of expert opinions and technical guidance. Once improvements had been carried out and the innovations had been standardized, those that had reached the relevant standards were introduced to health care facilities based on the need during the crisis. This cycle of selection, advice and guidance, and appraisal of any innovation is to be a sustainable and continuous process.

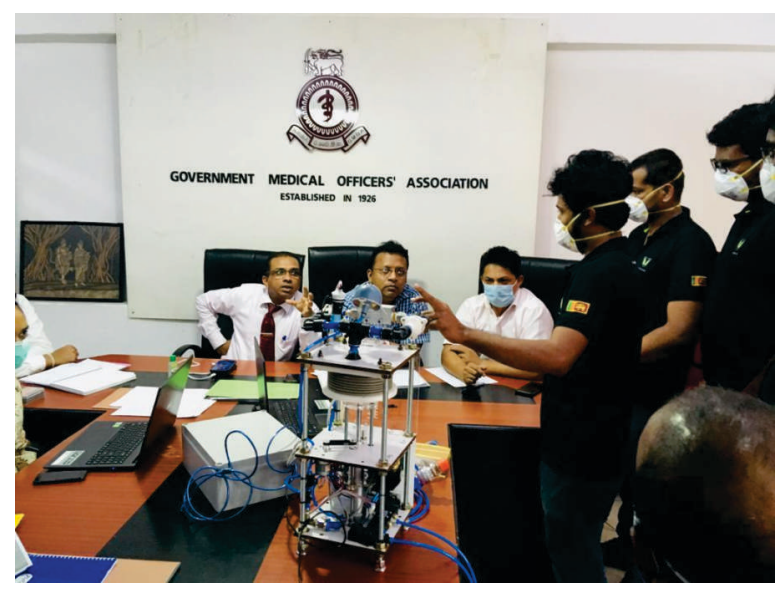

Figure 1: Mechanical ventilator produced by a group of inventors

(Vega Innovations) - initial meeting

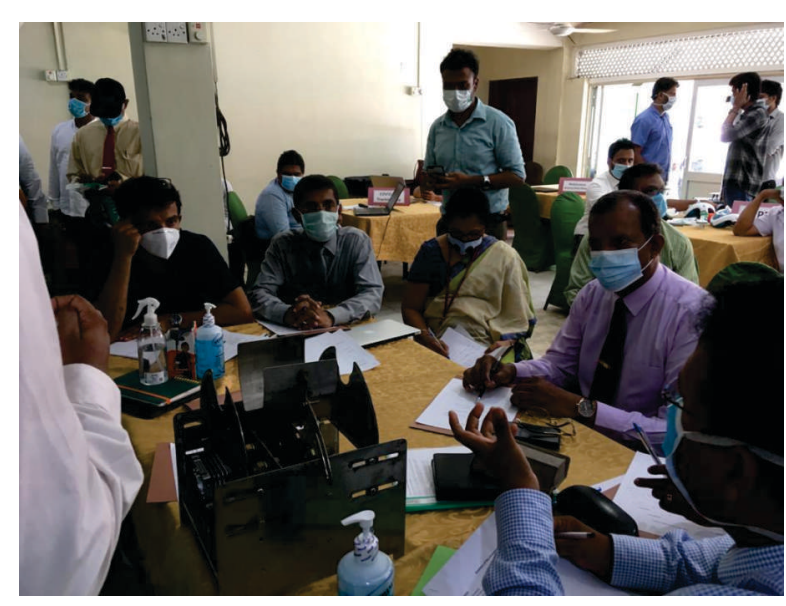

Figure 2: Discussions of the expert panel 


\section{The types of innovations}

Among the innovations which were showcased, several noteworthy products were observed. Mechanical ventilators and intensive care unit (ICU) beds were such innovations. Four teams produced mechanical ventilators and two have reached the minimum standards of the expert committee. Both these ventilators have reached the level that they could be used in an emergency whilst one of them was developed as a transport ventilator for use in ambulances. One team of innovators produced an ICU bed considering the local requirements and it is at a stage that it could be commercially produced and exported.

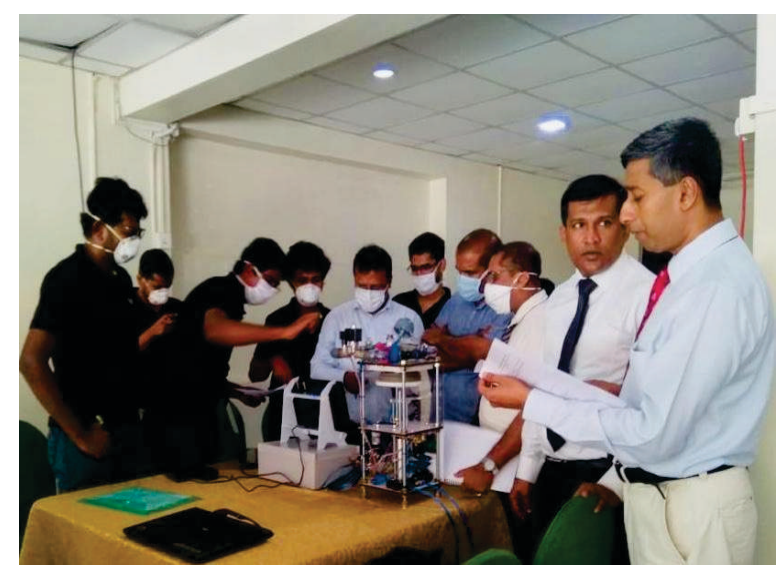

Figure 3: Mechanical ventilator produced by

'Vega Innovations' at the stage of assessing minimum requirements

Mobile applications that can trace the contacts of the COVID-19 patients and the suspects were developed and subsequently introduced to the COVID-19 national centre and municipal councils of some highrisk areas.

The personal protective equipment (PPE) kit developed during this program using hospital waste bags was immediately put to manufacture with the assistance of the Sri Lanka Army and Sri Lanka Air Force fulfilling a requirement of the health care staff. Further collaborations took place in developing various kinds of PPE including PPE kits, masks and face shields. Tele-medicine with video-assisted devices was also introduced for doctor-patient communication which would be helpful for healthcare staff during this pandemic. Automated artificial manual breathing units (AMBU) with graphical representation of the AMBU ventilation pressure curves were developed during this venture. A mechanical cardio-pulmonary resuscitation (CPR) machine was also produced and that would minimize the patient contact with the health care worker during the management of COVID-19 complications.

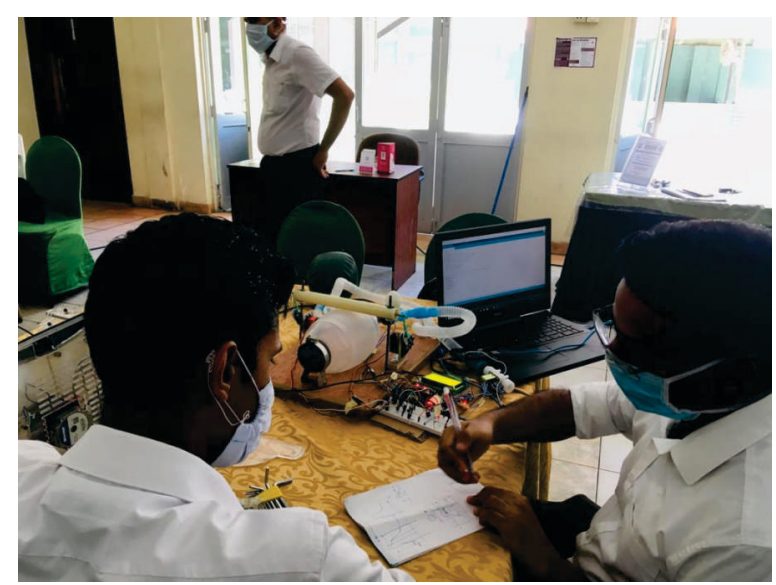

Figure 4: Two inventors

(Dr Kalsara Abeysekara and

Engineer Mr AGU Sampath) combining their innovations of an ambu bag assisted device into a better product

Several other innovations including examination chambers and sterilization chambers were successfully produced during this programme and directed to suitable healthcare facilities.

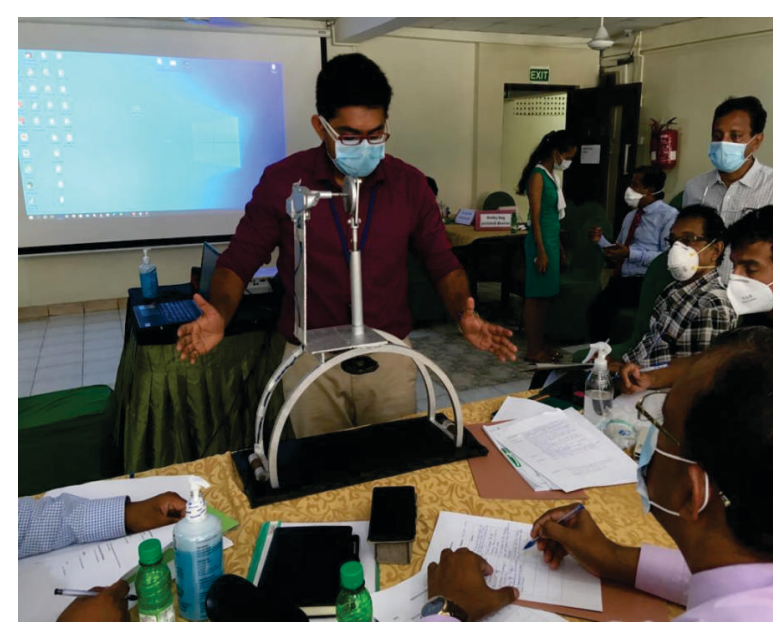

Figure 5: An inventor (Dr Dilshan Abeywardhana) presenting the mechanical CPR machine to the expert panel 


\section{Strengths and challenges}

This programme can be considered a success as it enabled approximately 30 innovations to be developed. Those that were developed to a satisfactory level included; ventilators (4), ambulatory bag assisted devices (2), mechanical CPR device (1), disinfectant methods (6), alternatives for increasing efficacy of COVID-19 testing (2), ICU beds (1), examination chambers (2), video-assisted devices (1), PPE (5), effective oxygen delivery system (1), safety band for quarantined persons (1) and a COVID-19 software (4). Whilst giving a platform to showcase and highlight their innovations, it provided an opportunity to develop and improve their products and subsequently ensure that they would be utilized in a suitable setting. It also created an opportunity to create innovations which were need-based and country-specific, thus assisting the nation in its time of need. It also promotes the sustainable development of national innovations.

During the procedure, certain difficulties had to be overcome. As ports of entry were shut down the innovators faced the difficulty of obtaining required parts. This was overcome by introducing to collaborators to obtain the necessary parts. Most of the innovators needed biomedical knowledge for their innovations. The programme enabled them to get necessary guidance from the medical specialists and technical specialists. Subsequent to this, discussions took place between the Ministry of the Health, Sri Lanka and SHRI regarding this programme. As such, discussions have taken place to bring about this collaboration between the Ministry and SHRI and as such a committee has been formulated to carry on this programme in a sustainable manner.

\section{Conclusions}

We hope to continue this endeavour in a sustainable manner, providing a platform for Sri Lankan innovators and researchers to present their innovations, develop them, enable them to reach the necessary standards and bring about their production.

\section{Author Declaration}

Acknowledgements: We would like to acknowledge the assistance given by the various expert panels involved in assessment and advising of the innovators and the innovators themselves for their enthusiastic participation.

Author contributions: AP: Initiation of the programme, providing leadership and assessment of innovations; PC: Organization, coordination and planning of the programme; $\mathrm{UN}$ : Coordination of the programme and writing the article; NdeL: Writing the article and coordination of the programme; BK: Writing the article and coordination of the programme; SA: Writing the article and organization of the programme; HS: Coordination and assessment of innovations; NS: Coordination and organization of the programme; SF: Coordination and organization of the programme; HA: Coordination and organization of the programme; YR: Coordination of programme and collating of data; RD: Coordination of the programme and collating of data; CE: Coordination and organization of the programme; DR: Coordination and organization of the programme

\section{References}

1. Ramiah D. 10 Ways Technology is Helping To Fight the Coronavirus. Available from: https://www. cn.undp.org/content/china/en/home/ourpers pective/ ourperspectivearticles/2020/10-ways-technology-ishelping-to-fight-the-coronavirus.html.Accessed 29 April 2020.

2. United Nations Development Programme (UNDP). Available from: https://www.undp. org/content/ undp/en/home/sustainable-develop ment-goals/ goal-9-industry-innovation -and-infrastructure.html. Accessed 28 April 2020.

3. Wang M, Cao R, Zhang L, Yang X, Liu J, Xu M, Shi Z, Hu Z, Zhong W, Xiao G. Remdesivir and chloroquine effectively inhibit the recently emerged novel coronavirus (2019-nCoV) in vitro. Cell Research 2020; 30(3): 269-271. DOI: 10.1038/ s41422-020-0282-0. 